\title{
Trial of labour or elective repeat caesarean delivery:are women making an informed decision at Kenyatta national hospital?
}

Phocas Biraboneye $\mathrm{S}^{1 *}$, Omondi Ogutu${ }^{2}$, Jos van Roosmalen ${ }^{3}$, Samson Wanjala ${ }^{4}$, Kizito Lubano ${ }^{5}$ and John Kinuthia ${ }^{6}$

\begin{abstract}
Background: Trial of labour is a safe option for most women after one previous caesarean delivery. However, the proportion of women attempting trial of labour after previous caesarean delivery (TOLAC) has been declining in many countries. In addition, women with prior caesarean delivery appear to know little regarding their mode of delivery and healthcare providers' recommendations. The doctors' preferences exert a strong influence on patient's decision whether or not to pursue TOLAC. In Kenya, it is unclear whether women who opt for trial of labour after caesarean delivery (TOLAC) or elective repeat caesarean delivery (ERCD) do that based on clear understanding of risks and benefits of both modes of delivery. This study aimed at determining whether patients with one previous caesarean delivery make an informed decision on preferred mode of delivery following their interactions with doctors.
\end{abstract}

Methods: A cross-sectional descriptive study was carried out on 202 pregnant women with one previous caesarean delivery at Kenyatta National Hospital (KNH) antenatal clinic. Data was collected from both the patients' records and women were interviewed using a structured questionnaire.

Results: Out of 202 women with mean age of 30.2 years 136 (67.2\%) chose Elective Repeat Caesarean Delivery (ERCD), while 66 (32.8\%) opted for TOLAC. Only 61/202 (30.6\%; 95\% C.I: 24.4 to 37.6\%) made informed decisions. Few women (65: 32.2\%) knew that the chance of successful TOLAC was high (60-80\%) and 97 (48\%) were not aware of the chances for a successful TOLAC. More than half of the women (109: 53.9\%) were unaware of the risk of uterine rupture after one previous delivery and only few patients (64: $31.7 \%)$ knew that the risk of uterine rupture in TOLAC is low ( $<1 \%)$. The majority of the women (112: 55.4\%) did not know that the indications for previous caesarean delivery are an important factor in determining the chance of a successful Vaginal Birth after Caesarean Delivery (VBAC). For 47(23.3\%) of the women, there was no documented indication for the previous caesarean delivery. The women's mode of delivery was significantly associated with the preference of the counseling doctor $(p<0.001)$ and their qualification $(p=0.020)$. Only 23 (11.4\%) women signed the consent form for ERCD while none of the women for TOLAC signed any consent form.

Conclusions: There was an overall lack of information on both modes of delivery while doctor's preferences affected women's decisions. Only just under one third of the women made an informed decision. There is a need to develop clear standard protocols and checklists for information to be disseminated to doctors and all patients with previous caesarean deliveries in subsequent pregnancies in Kenya.

\footnotetext{
* Correspondence: biraboneye@gmail.com

${ }^{1}$ Department of Obstetrics and Gynaecology, Jeanne de Navarre Hospital

Center, Château-Thierry, France

Full list of author information is available at the end of the article
} 


\section{Background}

A successful trial of labour culminating in vaginal birth, a failed trial resulting in an emergency repeat caesarean delivery, or an elective repeat caesarean delivery are the three possible outcomes for the woman who has had a prior caesarean section. Planning the mode of delivery should be addressed early during prenatal care, and can begin even pre-conceptionally. With either approach, women who have undergone a prior caesarean delivery are at risk for serious maternal and perinatal complications and should be counselled about these risks [1].

In the USA, Federal Acts and regulations as well as professional guidelines clearly demonstrate that every pregnant woman has the right to base her maternity care decisions on accurate, up-to-date, comprehensible information [2]. Informed consent is "the willing acceptance of a medical intervention by a patient after adequate disclosure by the physician of the nature of the intervention and its alternatives with its risks and benefits " [3, 4]. It is thus more than just signing a consent form.

The decision for elective repeat caesarean delivery or trial of labour should be made by the woman in consultation with her provider. Both clinicians and patients desire individualized information about the chance of successful TOLAC and the balance between the risk of maternal or foetal morbidity if TOLAC is unsuccessful and the risk of maternal and foetal morbidity with ERCD [5]. Women in the USA report that their healthcare providers' recommendations and preferences exert a strong influence on their decision whether or not to pursue TOLAC [6].

This information is also important on a population level, especially in the setting of rising caesarean delivery rates, as selection of candidates who are most likely to deliver vaginally after a previous operation can minimize the costs of ERCD and failed TOLAC [5]. In fact, improving patient education may not affect the increasing section rate; it would, however, empower women to make a well informed, educated decision [7].

The aim of this study was to determine whether patients with one previous caesarean delivery were making an informed decision about their preferred mode of delivery at "Kenyatta National Hospital".

\section{Methods}

\section{Study sites}

The study was conducted in the Antenatal Clinic at $\mathrm{KNH}$, which is the national referral hospital located in Nairobi. It is also the main teaching hospital for the College of Health Sciences, University of Nairobi. The hospital caters for patients from Nairobi and its neighbourhoods as well as referrals from other hospitals in the country.

\section{Study design}

This was a cross-sectional descriptive study that targeted pregnant women with one previous caesarean delivery attending ANC at $\mathrm{KNH}$ for delivery from September 2013 to January 2014. On average approximately 50 women with one previous caesarean delivery attend ANC per month.

\section{Data collection}

Consenting women completed structured questionnaires to assess their demographic characteristics, awareness about risks and benefits of both modes of delivery, doctors' preferences, knowledge about complications following prior caesarean delivery as well as indications of previous caesarean delivery, and knowledge about the mode of delivery in the current pregnancy. Data abstraction was also done from patients' records through a structured questionnaire to assess parity, level of provider, family planning goals, and relevant clinical examination including estimated foetal weight, obstetrical ultrasound data, timing on decision of mode of delivery and any other medical or obstetric complication (Additional file 1).

\section{Statistical analysis}

Data was entered into a micro-computer through Epidata designed database and exported to STATA 11.0 and Statistical Package for Social Science (SPSS-20) for analysis. Comparative analysis focused on patient knowledge, baseline characteristics, obstetric characteristics and antenatal care provided, and chosen mode of delivery. $P<0.05$ was considered statistically significant.

\section{Ethics}

Approval was obtained from the $\mathrm{KNH} / \mathrm{UoN}$ Ethics and Research committee before carrying out the study. Informed consent of women was obtained before participating in the study. Antenatal care was provided to all women regardless of whether they consented or declined to participate in the study. The records were coded and anonymised. The information collected remained confidential and was only used for the purpose of the study. No incentives were given to the study subjects.

\section{Results}

\section{Socio-demographic characteristics}

A total of 202 women participated in the study with a mean age of 30.2 years. The highest proportion of women $(77 ; 38.1 \%)$ was in the group between 30 and 34 years (Table 1). Most women were married (94\%). Many women $(n=92 ; 45.6 \%)$ had secondary level of education and $46 \%$ of the participants were selfemployed. The majority of women with one previous caesarean delivery were para one $(75.7 \%)$. The outcome 
Table 1 Socio-demographic characteristics of the study participants

\begin{tabular}{ll}
\hline Parameters & $N(\%)$ \\
\hline Woman's age (years) & $25(12.4 \%)$ \\
$20-24$ & $64(31.7 \%)$ \\
$25-29$ & $77(38.1 \%)$ \\
$30-34$ & $36(17.8 \%)$ \\
$>35$ & \\
Educational level & $38(18.8 \%)$ \\
Primary & $92(45.6 \%)$ \\
Secondary & $72(35.6 \%)$ \\
University & \\
Marital Status & $190(94.0 \%)$ \\
Married & $10(5.0 \%)$ \\
Single & $2(1.0 \%)$ \\
Separated & \\
Occupation & $49(24.3 \%)$ \\
Employed & $92(45.5 \%)$ \\
Business /self employed & $2(1 \%)$ \\
Student & $59(29.2 \%)$ \\
Housewive &
\end{tabular}

of the previous caesarean delivery was a live birth for $82.1 \%$. About $15.8 \%(n=32)$ reported medical or obstetric complications following the previous caesarean delivery, with $39.5 \%$ among them reporting early neonatal death. The majority of the women $(89.6 \%)$ opted for no contraceptive choice following the current delivery, with only $5.9 \%$ of the women preferring bilateral tubal ligation. Before attending ANC $-\mathrm{KNH}, 47 \%$ of the patients preferred ERCD as mode of delivery while $42.6 \%$ of the patients preferred TOLAC (Table 2).

\section{Antenatal clinical assessment}

Non reassuring foetal heart rate (NRFS) was the most common indication for the previous caesarean delivery documented at $27.2 \%$ (Table 3). However, for $23.3 \%$ of the women there was no documented indication. The medical or obstetric complications postpartum were not documented for the majority (98\%). During the time of decision of mode of delivery, the estimated foetal birth weight was not documented in $90.6 \%$ and only $11.4 \%$ of the consent forms for ERCD was signed and documented in the file, while patients for TOLAC did not sign any consent form.

\section{Participants' knowledge on risks and benefits of both modes of delivery.}

On complications of surgery, most women knew little about complications of anaesthesia (8.3\%), injury to organs, severe haemorrhage, hysterectomy and even
Table 2 Obstetric characteristics of the study participants

\begin{tabular}{ll}
\hline Parameters & $N(\%)$ \\
\hline Woman's parity & $153(75.7 \%)$ \\
1 & $45(22.3 \%)$ \\
$2-3$ & $4(2 \%)$ \\
$>3$ & \\
Outcome of previous caesarean delivery & $166(82.1 \%)$ \\
live infant & $4(2 \%)$ \\
Live infant in distress & $1(0.5 \%)$ \\
Premature baby & $11(5.4 \%)$ \\
Still birth & $10(5 \%)$ \\
Neonatal death & $6(3 \%)$ \\
Infant death & $4(2 \%)$ \\
Not documented & \\
Medical or obstetrical complications after the previous c/s according to \\
the participant's interview $(n=32)$ \\
Bleeding (PPH) & $3(7.9 \%)$ \\
Eclampsia & $8(21.1 \%)$ \\
Maternal infections & $8(21.1 \%)$ \\
Death of the baby(neonatal death) & $15(39.5 \%)$ \\
Burst abdomen & $3(7.9 \%)$ \\
Post partum psychosis & $1(2.6 \%)$ \\
Women's family planning method choice following the current delivery \\
Bilateral Tubal Ligation & $12(5.9 \%)$ \\
Natural & $1(0.5 \%)$ \\
Pills & $6(3 \%)$ \\
Injections & $2(1 \%)$ \\
\hline & $181(89.6 \%)$ \\
\hline &
\end{tabular}

maternal death (1.1\%) as associated risks of repeat caesarean delivery.

Only $32.2 \%$ of the women knew that the overall chances of success of TOLAC is $>50 \%$. Regarding the risks of uterine scar rupture, more than half of the women (53.9\%) did not know about this risk, while only $31.7 \%$ knew that the risk is very low $(<1 \%)$, but increasing with the number of repeat caesarean deliveries (Table 4). More than half of the women (55.4\%) did not know that the reasons for previous caesarean delivery are an important factor in determining the chance of successful TOLAC.

The majority of the participants (70.3\%) had attended $\mathrm{ANC}$ at $\mathrm{KNH}$ more than three times and in $62.4 \%$ of the 
Table 3 Antenatal clinical assessment of women with one previous caesarean delivery attending KNH ANC

\begin{tabular}{ll}
\hline Parameters & $N(\%)$ \\
\hline Medical or obstetrical complication documented during ANC \\
Preeclampsia & $8(4 \%)$ \\
Diabetes & $2(1 \%)$ \\
Anemia & $1(0.5 \%)$ \\
HIV-positive & $7(3.4 \%)$ \\
Placenta praevia & $2(1 \%)$ \\
Malpresentation & $5(2.5 \%)$ \\
Fibroids & $5(2.5 \%)$ \\
No complication documented/indicated & $172(85.1 \%)$
\end{tabular}

Documented reasons for the previous caesarean delivery

$\begin{array}{ll}\text { CPD/big baby } & 31(15.3 \%) \\ \text { Malpresentation } & 15(7.4 \%) \\ \text { APH } & 4(2 \%) \\ \text { Failed induction } & 18(8.9 \%) \\ \text { Prolonged labour } & 32(15.8 \%) \\ \text { Non reassuring foetal distress } & 55(27.2 \%) \\ \text { Not documented } & 47(23.3 \%)\end{array}$

Medical or obstetrical complication postpartum documented after the previous caesarean delivery

$\begin{array}{ll}\text { Infections } & 2(1 \%) \\ \text { Preeclampsia } & 2(1 \%) \\ \text { Not documented } & 198(98 \%)\end{array}$

Estimated foetal birth weight $(\mathrm{Kg})$ clinically or by $\mathrm{U} / \mathrm{S}$ documented at the time of the decision of mode of delivery

$\begin{array}{ll}<3.5 & 15(7.4 \%) \\ \geq 3.5 & 4(2 \%) \\ \text { Not documented } & 183(90.6 \%)\end{array}$

Consent form signed and documented in the file at the time of decision for mode of delivery

$\begin{array}{ll}\text { Yes (Women admitted for ERCD from ANC) } & 23(11.4 \%) \\ \text { Booked in elective diary } & 92(45.8 \%) \\ \text { Not documented } & 86(42.8 \%)\end{array}$

cases women were informed on ERCD as the only mode of delivery.

Few women knew that a classical scar (7 out of 116) and unavailability of $24 \mathrm{~h}$ theatre and skilled providers $(1 / 116)$ are reasons to consider recommending ERCD (Table 5). The majority of doctors at ANC- KNH were senior house officers (174: 86.1\%), while consultants were represented at 28 (13.9\%).

The decision made on mode of delivery during ANC was ERCD in 136 (67.2\%) women and trial of labour in 66 (32.8\%). After counselling during ANC a significant reduction in the choice of TOLAC was observed from $42.6 \%$ to $32.8 \%$ with an increase from $47 \%$ to $67.2 \%$ of ERCD (Table 6).
Table 4 Knowledge on risks and benefits of both modes of delivery amongst one previous caesarean delivery women attending $\mathrm{KNH}$ ANC

\begin{tabular}{ll}
\hline Parameters & $N(\%)$ \\
\hline $\begin{array}{l}\text { Women's knowledge on risks associated with repeat C/S than TOLAC } \\
\text { Increased blood loss }\end{array}$ & $124(28.4 \%)$ \\
High risk of infection & $106(24.3 \%)$ \\
Complication of anaesthesia & $36(8.3 \%)$ \\
Uterine scar rupture in case of big baby & $10(2.3 \%)$ \\
Injury to organs & $5(1.1 \%)$ \\
Recovery is longer & $140(32.2 \%)$ \\
Limb numbness & $15(3.4 \%)$
\end{tabular}

Women's knowledge on risks associated with TOLAC than ERCD $(n=155)$

$\begin{array}{ll}\text { Uterine scar rupture resulting in emergency C/S } & 54(20.8 \%) \\ \text { Failed trial of labour } & 114(44 \%) \\ \text { Uterine rupture is > with VBAC than repeat C/S } & 81(31.3 \%) \\ \text { Increased blood loss } & 5(1.9 \%) \\ \text { Increased risk of infection } & 2(0.8 \%) \\ \text { Foetal death } & 3(1.2 \%)\end{array}$

Women's knowledge regarding overall chances of success of TOLAC

$\begin{array}{ll}\text { Very high }(>50 \%) & 65(32.2 \%) \\ \text { Very low }(<25 \%) & 40(19.8 \%) \\ \text { Don't know } & 97(48 \%)\end{array}$

Women's knowledge regarding the risks of uterine scar rupture

$\begin{array}{ll}\text { Very low }(<1 \%) \text { but increased with number of c/s } & 64(31.7 \%) \\ \text { Very high }(>50 \%) & 29(14.4 \%)\end{array}$

Women's knowledge on recovery from vaginal delivery against repeat $C / S$

$\begin{array}{ll}\text { Same } & 1(0.5 \%) \\ \text { Longer for repeat C/S } & 166(82.2 \%) \\ \text { Longer for vaginal delivery } & 2(1 \%) \\ \text { I don't know } & 33(16.3 \%)\end{array}$

Reasons for previous $\mathrm{c} / \mathrm{s}$ as important factor in determining the chance of successful TOLAC according to the participants

$\begin{array}{ll}\text { Yes } & 60(29.7 \%) \\ \text { No } & 30(14.9 \%) \\ \text { Don't know } & 112(55.4 \%)\end{array}$

In Table 7 , the minimum proposed criteria for informed decision on mode of delivery at $\mathrm{KNH}$ are given. On average, it was reported that 61 (30.2\%; 95\% CI: 24 to $37 \%$ ) of the women were making informed decisions.

There was no association with preferred mode of delivery in terms of women's age $(p=0.654)$, level of education $(p=0.224)$, marital status $(p=0.419)$ number of ANC visits $(p=0.574)$, patient's parity $(p=0.286$, and 
Table 5 Number of antenatal visits and information provided to women with one previous caesarean delivery attending KNH ANC

\begin{tabular}{ll}
\hline Parameters & $N(\%)$ \\
\hline $\begin{array}{l}\text { Number of ANC visits at the time of recruitment } \\
<3\end{array}$ & $60(29.7 \%)$ \\
$\geq 3$ & $142(70.3 \%)$ \\
Women informed on available options of mode of delivery & \\
Elective repeat c/s & $126(62.4 \%)$ \\
Trial of labour & $61(30.2 \%)$ \\
None & $15(7.4 \%)$ \\
Women counselled on reasons for ERCD against TOLAC ( $n=116)$ \\
Big baby (>3.5 kg) & $21(18.1 \%)$ \\
Classical scar & $7(6 \%)$ \\
Small pelvis & $15(12.9 \%)$ \\
Unavailability of $24 \mathrm{~h}$ theatre/blood transfusion/skilled & $1(0.9 \%)$ \\
doctors and anaesthetists & \\
Mal-presentation/breech presentation & $11(9.5 \%)$ \\
Bad obstetric history & $3(2.6 \%)$ \\
Choice of BTL & $2(1.7 \%)$ \\
Placenta praevia & $21(18.1 \%)$ \\
Don't know & $35(30.2 \%)$
\end{tabular}

Women counselled at discharge after previous $C / S$ on reasons ERCD is recommended in subsequent pregnancy $(n=19)$

$\begin{array}{ll}\text { Small pelvis } & 13(68.5 \%) \\ \text { Classical uterine incision } & 2(10.5 \%) \\ \text { High risk of uterine rupture if any VBAC } & 2(10.5 \%) \\ \text { BTL would also be offered } & 2(10.5 \%) \\ \text { Counselling doctor preferred mode of delivery } \\ \text { perception of the participant) } \\ \text { None } & 44(21.8 \%) \\ \text { Elective repeat caesarean section } & 107(53 \%) \\ \text { Trial of labour } & 51(25.2 \%) \\ \text { Level of provider at ANC KNH } & 174(86.1 \%) \\ \text { Senior house officer } & 28(13.9 \%) \\ \text { Consultant obstetrician } & \end{array}$

patient occupation $(p=0.795)$.The following correlates were, however, significantly associated with the preferred mode of delivery: counselling doctor preferred mode of delivery $(p<0.001)$, women preferred mode of delivery before attending $\mathrm{KNH}(p<0.001)$ and level of care provider $(p=0.02)$ (Table 8$)$.

No association with preferred mode of delivery was found in terms of estimated foetal birth weight at the time of decision $(p=0.372)$ and knowledge on risks associated with repeat CS as compared to TOLAC $(p=0.482)$. However, knowledge of women regarding overall chances of success of TOLAC $(p<0.001)$, risk of uterine rupture in TOLAC $(p<0.001)$ and women's knowledge on recovery from vaginal delivery against
Table 6 Decision or choice of TOLAC and ERCD before attending $\mathrm{KNH}$ ANC and after counseling

\begin{tabular}{llll}
\hline Before KNH-ANC visit (TOLAC) & \multicolumn{3}{l}{ After ANC visit (TOLAC) } \\
& Yes & No & Total \\
Yes & 58 & 28 & $86(42.6 \%)$ \\
No & 8 & 108 & 116 \\
Total & $66(32.8 \%)$ & 136 & \\
Before KNH-ANC visit (ERCD) & After ANC visit (ERCD) & \\
& Yes & No & \\
Yes & 91 & 4 & $95(47 \%)$ \\
No & 45 & 62 & 107 \\
Total & $136(67.2 \%)$ & 66 & \\
\hline
\end{tabular}

repeat caesarean delivery $(p<0.001)$ were significantly associated with the preferred mode of delivery (Table 9).

\section{Discussion}

The study findings show that few women chose TOLAC and even fewer were making an informed decision. Most women preferred repeat caesarean delivery before attending $\mathrm{ANC}$ at $\mathrm{KNH}$ and this was significantly associated with the patient's choice after ANC counseling. Equally, women's mode of delivery was significantly linked with the preference of the counselling doctor and their qualification. Women appear to know little about their mode of delivery.

However, this study did not establish an association between preferred mode of delivery and women's demographic characteristics (age, educational level, marital status, occupation, parity) and number of antenatal visits.

A small number of women chose TOLAC probably because of inadequate information and influence of the counselling doctor from ANC. A recent study published by Sarah and collaborators has demonstrated the same findings [6]. The majority of the women did not make an informed decision at $\mathrm{KNH}$ and this was probably because of lack of adequate information provided in ANC or largely due to poor women counselling. This study proposes minimum criteria for an informed decision in a woman with one previous caesarean delivery attending $\mathrm{KNH}$. No similar studies involving clear criteria to determine whether they are making informed decisions have been performed.

However, worldwide the practice of obstetrics and gynecology has always faced special ethical questions in the implementation of informed consent [2]. More studies need to be done for a generalization of the proposed criteria. Most of the women did not know the overall chances of success (60-80\%) and the risks of uterine rupture $(<1 \%)$ with TOLAC. These findings are different from the study done by Sarah and collaborators in USA 
Table 7 Minimum criteria for a woman with one previous caesarean delivery to make an informed decision on mode of delivery at $\mathrm{KNH}$

\begin{tabular}{|c|c|}
\hline Criteria & $N(\%)$ \\
\hline \multicolumn{2}{|c|}{ Women informed on mode of delivery (available options) $(n=202)$} \\
\hline TOLAC & $61(30.2 \%)$ \\
\hline ERCD & $126(62.4 \%)$ \\
\hline Both & 0 \\
\hline \multicolumn{2}{|c|}{ Women's knowledge on factors influencing mode of delivery $(n=116)$} \\
\hline Classical scar as a reason for ERCD & $7(6 \%)$ \\
\hline Small pelvis as a reason for ERCD & $15(12.9 \%)$ \\
\hline Big baby as a reason for ERCD & $21(18.1 \%)$ \\
\hline $\begin{array}{l}\text { Current medical or obstetric complications as a reason } \\
\text { for ERCD }\end{array}$ & $30(25.9 \%)$ \\
\hline Adequacy of facility for delivery (A 24 h-theater...) & $1(0.9 \%)$ \\
\hline \multicolumn{2}{|c|}{$\begin{array}{l}\text { Women's knowledge on success and risk of uterine rupture in TOLAC } \\
(n=202)\end{array}$} \\
\hline Patient knowledge on overall chance of TOLAC success & $65(32.2 \%)$ \\
\hline Patient knowledge on risk of uterine rapture in TOLAC & $64(31.7 \%)$ \\
\hline $\begin{array}{l}\text { Reasons of previous caesarean as factor of success for } \\
\text { TOLAC }\end{array}$ & $60(29.7 \%)$ \\
\hline \multicolumn{2}{|l|}{ Women's knowledge on risks of ERCD over TOLAC $(n=163)$} \\
\hline Increased blood loss & $124(76.1 \%)$ \\
\hline High risk of infection & $106(65.0 \%)$ \\
\hline Complication of anaesthesia & $36(22.1 \%)$ \\
\hline Injury to organ & $5(3.1 \%)$ \\
\hline Recovery is longer & $140(85.9 \%)$ \\
\hline $\begin{array}{l}\text { Consent form signed and documented in the patient file } \\
(n=202)\end{array}$ & $23(11.4 \%)$ \\
\hline
\end{tabular}

[6] and the difference is probably due to Sarah's questionnaire administered to the women at admission and not immediately during the antenatal visits.

There was a significant correlation with women's preferred mode of delivery before attending ANC KNH and chosen mode of delivery after ANC counseling $(p<0.001)$. This was probably due to alternative sources of information and poor antenatal education regarding both modes of delivery. Most factors influencing mode of delivery in women not counselled on mode of delivery during antenatal visits were identified as friend advice and internet information. No similar study has shown the alternative source of information besides health providers counselling on decision making. In this study majority of the senior house officers were offering repeat caesarean delivery due to probably less experience and lack of standard guidelines in management of a woman with one previous caesarean delivery.

According to Wells (2010), physicians that did not offer VBAC were also more likely to be practicing $<10$ years, have been involved in a law suit related to caesarean
Table 8 Antenatal and obstetric correlates associated with the preferred mode of delivery amongst one previous caesarean delivery women attending $\mathrm{KNH}$ ANC

\begin{tabular}{llll}
\hline Parameters & $\begin{array}{l}\text { ERCD } \\
n=136\end{array}$ & $\begin{array}{l}\text { TOLAC } \\
n=66\end{array}$ & P-value \\
\hline Women's parity & & & \\
1 & $104(76.5 \%)$ & $49(74.2 \%)$ & 0.286 \\
$2-3$ & $28(20.6 \%)$ & $17(25.8 \%)$ & \\
$>3$ & $4(2.9 \%)$ & 0 &
\end{tabular}

Number of ANC visits at the time of recruitment

$\begin{array}{lll}<3 & 35(26.3 \%) & 19(30.2 \%) \\ \geq 3 & 98(73.7 \%) & 44(69.8 \%)\end{array}$

Counselling doctor preferred mode of delivery

$\begin{array}{lll}\text { None } & 29(21.3 \%) & 15(22.7 \%)\end{array}$

Repeat caesarean section $\quad 107(78.7 \%) \quad 0$

$\begin{array}{lll}\text { Vaginal delivery } & 0 & 51(77.3 \%)\end{array}$

Women's preferred mode of delivery before attending $\mathrm{KNH}$

$\begin{array}{lll}\text { Trial of labour } & 28(20.6 \%) & 58(87.9 \%) \\ \text { Elective repeat c/s } & 91(66.9 \%) & 4(6.1 \%) \\ \text { Not sure } & 14(10.3 \%) & 3(4.5 \%) \\ \text { Any } & 3(2.2 \%) & 1(1.5 \%)\end{array}$

Level of provider at ANC KNH

$\begin{array}{lll}\text { Senior house officer } & 123(90.4 \%) & 51(78.5 \%) \\ \text { Consultant } & 13(9.6 \%) & 14(21.5 \%)\end{array}$

delivery or have experienced uterine rupture with maternal or foetal complications [8]. Most inexperienced providers tend to have bias towards informed consent of patients with one previous caesarean delivery. In addition, some patients having limited understanding of pregnancy and child birth would be easily influenced by the most senior doctors. However some challenges associated with informed consent are to be remembered: information that may be considered necessary or desirable in formally educated urban populations may be of little relevance in less formally educated or rural populations, or vice versa. Also, in some cultures it might not be customary to provide certain forms of information, such as describing uncertainty about the effectiveness of the treatment, or information about possible alternative treatments.

Some of the providers therefore apply the dictum of Craigin: "Once a caesarean, always a caesarean" [9]. Because informed consent laws and principles do not specify the amount of information that must be disclosed, physicians might find it useful to know what they have to disclose.

In literature, advanced maternal age, single marital status and less than 12 years education are associated with a reduced likelihood of successful TOLAC [10]. In addition, this study found a limited documentation in patient's files. Proper documentation is a useful tool in 
Table 9 Women's knowledge correlates associated with the preferred mode of delivery amongst one previous caesarean delivery patients attending KNH ANC

\begin{tabular}{|c|c|c|c|}
\hline Parameters & $\begin{array}{l}\text { ERCD } \\
n=136\end{array}$ & $\begin{array}{l}\text { TOLAC } \\
n=66\end{array}$ & $P$-value \\
\hline \multicolumn{4}{|c|}{ Women's knowledge regarding the risks of uterine scar rupture } \\
\hline Very low $(<1 \%)$ but increased with number of $c / s$ & $17(26.6 \%)$ & $47(73.4 \%)$ & \multirow[t]{3}{*}{0.001} \\
\hline Very high $(>50 \%)$ & $27(93.1 \%)$ & $2(6.9 \%)$ & \\
\hline Don't know & $92(84.4 \%)$ & $17(15.6 \%)$ & \\
\hline \multicolumn{4}{|c|}{ Women's knowledge regarding overall chances of success of TOLAC } \\
\hline Very high (>50\%) & $12(8.8 \%)$ & $53(80.3 \%)$ & \multirow[t]{3}{*}{0.001} \\
\hline Very low (<25\%) & $40(29.4 \%)$ & 0 & \\
\hline Don't know & $84(61.8 \%)$ & $13(19.7 \%)$ & \\
\hline \multicolumn{4}{|c|}{ Women's knowledge on recovery from vaginal delivery against repeat $C / S$} \\
\hline Same & - & $1(1.5 \%)$ & \multirow[t]{4}{*}{0.001} \\
\hline Longer for repeat $\mathrm{C} / \mathrm{S}$ & $103(75.7 \%)$ & $63(95.5 \%)$ & \\
\hline Longer for a vaginal delivery & $2(1.5 \%)$ & 0 & \\
\hline I don't know & $31(22.8 \%)$ & $2(3 \%)$ & \\
\hline \multicolumn{4}{|c|}{ Estimated foetal birth weight in $\mathrm{Kg}$ clinically or by $\mathrm{U} / \mathrm{S}$ at the time of the decision of mode of delivery } \\
\hline$<3.5$ & $10(7.4 \%)$ & $5(7.6 \%)$ & \multirow[t]{3}{*}{0.372} \\
\hline$\geq 3.5$ & $4(2.9 \%)$ & - & \\
\hline Not documented & $122(89.7 \%)$ & $61(92.4 \%)$ & \\
\hline \multicolumn{4}{|c|}{ Women's awareness on risks associated with repeat C/S than TOLAC } \\
\hline Increased blood loss & $76(26.6 \%)$ & $48(32 \%)$ & \multirow[t]{7}{*}{0.482} \\
\hline High risk of infection & $65(22.7 \%)$ & $41(27.3 \%)$ & \\
\hline Complication of anaesthesia & $26(9.1 \%)$ & $10(6.8 \%)$ & \\
\hline Rupture in case of big baby & $8(2.8 \%)$ & $2(1.3 \%)$ & \\
\hline Injury to organs & $3(1 \%)$ & $2(1.3 \%)$ & \\
\hline Recovery is longer & $96(33.6 \%)$ & $44(29.3 \%)$ & \\
\hline Limb numbness & $12(4.2 \%)$ & $3(2 \%)$ & \\
\hline
\end{tabular}

informed consent. Without proper documentation a patient may not get adequate and relevant information. Researchers have also shown that the patients may not accurately remember all the facts disclosed in a discussion $[11,12]$ In practice, there is no consent form for TOLAC patients available in Kenya. Few patients signed the consent form for ERCD while none did for TOLAC. Consent forms should be available at the moment of decision to prove that the patient was given information, understood and consented.

Some of the main limitations of this study are the small sample size and lack of standardization in women counselling. However, this study has two major strengths: it is original and proposes minimum criteria for an informed decision in women with prior caesarean delivery attending $\mathrm{KNH}$. Data was obtained from an institution offering VBAC and the population was not only more educated but also more urbanized and middle class than the average across the country. The results may therefore represent a better informed population suggesting wider knowledge gaps throughout the country. This study should be considered as a preliminary evaluation of current practice and patterns. It is intended therefore, to provoke further interest in the subject of making informed decisions by women with previous caesarean deliveries.

\section{Conclusions and recommendations}

\section{Conclusions}

There is overall lack of information on both modes of delivery while doctor's preference affects patient's decision. There is lack of documentation in patient's files as well on minimum proposed criteria for informed decision at $\mathrm{KNH}$.

\section{Recommendations}

Develop a standard protocol and policy for management of women with a previous caesarean section attending $\mathrm{KNH}$. Need for training of providers using such a protocol on the importance of documentation. 


\section{Additional file}

Additional file 1: Questionnaire. (DOCX $31 \mathrm{~kb}$ )

\begin{abstract}
Abbreviation
ANC: Antenatal Clinic; C/S: Cesarean Section; ERC: Ethics Research Committee; ERCD: Elective Repeat Cesarean Delivery; KNH: Kenyatta National Hospital; MD: Medical Doctor; MMed: Master in Medicine; RCD: Repeat Cesarean Delivery; RCOG: Royal College of Obstetricians and Gynecologists; SPSS: Statistical Package for Social Science; TOL: Trial of Labor; TOLAC: Trial of Labor after Cesarean Delivery; USA: United States of America; VBAC: Vaginal Birth after Cesarean Delivery
\end{abstract}

\section{Acknowledgements}

We wish to thank the Research program Kenyatta National Hospital for providing financial support. Also acknowledged is $\mathrm{KNH}$ - Reproductive Health Department for allowing the study to be conducted in the Antenatal clinic. Thanks and appreciation to Dr. Anne Marie Biraboneye, Dr. Humphrey Kunda, Dr. Jessica Uwera, Dr. Louise Kpoto and Dr. David Thuo who ploughed through several preliminary versions of the study findings, making critical suggestions and posing challenging questions. Last but not least, lots of thanks to all women who attended $\mathrm{KNH}$ ANC during the period of data collection, this work would not have been feasible if they did not consent.

\section{Funding}

The Research program Kenyatta National Hospital provided only the financial support during data collection and no incentive given to the authors as well to the study participants.

\section{Availability of data and materials}

The data on which this study has been based are publicly available via the repository of $\mathrm{KNH} / \mathrm{U} O \mathrm{~N}$ Ethics and Research committee.

\section{Authors' contributions}

PBS Conception and design; Acquisition of data; Analysis and interpretation of data; Drafting and revising the article and; Approval of the final version and Accountable for all aspects of the work. OO Design and acquisition of data; Analysis and interpretation of data; Drafting and revising the article; Approval of the final version and Accountable for all aspects of the work. JVR Drafting the article and revising it critically; Approval of the final version and Accountable for all aspects of the work. SW Interpretation of data; Approval of the final version and Accountable for all aspects of the work. $\mathrm{KL}$ Analysis and interpretation, Approval of the final version and Accountable for all aspects of the work. JK Revising the first draft, Approval of the final version and Accountable for all aspects of the work.

\section{Ethics approval and consent to participate}

This research study obtained approval from the KNH/UON Ethics and Research committee. Prior to the interview, women were asked to read and sign a consent form which informed them of the purpose of the study and were told that that participation was voluntary. Antenatal care was provided to all women regardless of whether they consented or declined to participate in the study. The data collection process was designed to be minimally intrusive and to use a minimum of the women's time to ensure social reputational harm was not inflicted. All data were stored in encrypted password protected spreadsheets, with access only to the lead researcher and research assistant. Upon completion of the data collection process, all data were anonymised and stripped of any identifiable information.

\section{Consent for publication}

Not applicable.

\section{Competing interests}

The authors declare that they have no competing interests.

\section{Publisher's Note}

Springer Nature remains neutral with regard to jurisdictional claims in published maps and institutional affiliations.

\section{Author details}

'Department of Obstetrics and Gynaecology, Jeanne de Navarre Hospital Center, Château-Thierry, France. ${ }^{2}$ Department of Obstetrics and Gynaecology, University of Nairobi, Nairobi, Kenya. ${ }^{3}$ Athena Institute, VU University Amsterdam, Amsterdam, The Netherlands. ${ }^{4}$ Department of Obstetrics and Gynaecology, University of Nairobi, Nairobi, Kenya. ${ }^{5}$ Kenya Medical Research Institute, Nairobi, Kenya. ${ }^{6}$ Department of research and programs, Kenyatta National Hospital, Nairobi, Kenya.

Received: 15 September 2016 Accepted: 31 July 2017

Published online: 15 August 2017

\section{References}

1. Wells EC, Cunningham GF. Choosing the route of vaginal delivery. www. uptodate.com. Accessed 4 Aug 2014.

2. ACOG. Updates of ethical decision making in obstetrics and gynaecology in ethics obstetrics and gynaecology. 2004

3. Paul S, Appelbaum M. Assessment of patients 'competence to consent to treatment. N Engl J Med. 2007:357:1834.

4. Michael S, Anthony B, Jillann F, et al. The guide to informed decisionmaking in healthcare. 1st ed; 2012. https://www.health.qld.gov.au/consent/ documents/ic-guide.pdf consulted August 2014

5. Torri DM. Use of calculators for predicting successful of labour after caesarean delivery. Up-to-date. 2014.

6. Sarah N, Matalon S, Rosenn B, et al. Trial of labour versus repeat: are patients making an informed decision? Am J Obstet Gynecol. 2012;207:204.

7. The American Academy of Pediatrics and the American College of Obstetricians and Gynecologists. Guidelines for Perinatal Care. J Contin Educ Heal Prof. 2007:8(2):111.

8. Wells C. Vaginal birth after delivery: views from a private practitioner. Semin Perinatol. 2010;34:245

9. Edwin C. Conservatism in obstetrics. New York Medical Journal. 1916;104:1.

10. Srinivas SK, Stamilio DM, Samuel MD, et al. Vaginal birth after caesarean delivery: does maternal age affect safety and success? Paediatr Perinat Epidemiol. 2007:21:114.

11. Robinson G, Meray A. Informed consent: recall by patients tested postoperatively. Ann Thorac Surg. 1976:22:209.

12. Herz DA, Looman JE, Lewis SK. Informed consent: is it a myth. Neurosurgery. 1992:30:453.

\section{Submit your next manuscript to BioMed Central} and we will help you at every step:

- We accept pre-submission inquiries

- Our selector tool helps you to find the most relevant journal

- We provide round the clock customer support

- Convenient online submission

- Thorough peer review

- Inclusion in PubMed and all major indexing services

- Maximum visibility for your research

Submit your manuscript at www.biomedcentral.com/submit
Biomed Central 